\title{
Co-opetition and the Stability of Competitive Contractual Strategic Alliance: Thinking Based on the Modified Lotka-Voterra Model
}

\author{
Xuemei Qing ${ }^{1}$ and Weiguo Zhang $^{1,2}$ \\ ${ }^{1}$ School of Economics and Business Administration, Chongqing University, \\ Chongqing 400040, China \\ ${ }^{2}$ College of Economics and Management, Southwest University, Chongqing 400715, \\ China \\ qingxuemeilx@126.com,wgzhang@cqu.edu.cn
}

\begin{abstract}
Co-opetition is the key feature of competitive contractual strategic alliances. Original competition, inter-alliance competition and cooperation constitute all together co-opetition relations in competitive contractual strategic alliance. Such relations dictate the stability of the alliance by means of affecting the profits of alliance partners. A modified Lotka-Voterra model is established using system dynamics, due to the similarity of enterprises and alliances to biological systems. According to the analysis of modified Lotka-Voterra model, we find: there exists stable boundary in alliance, the extent of co-opetition within an alliance determines its direction, i.e. differences in the extension of co-opetition result in the differences of alliance revolution; Co-opetition between alliance partners is not always the same, but changing constantly. The system evaluates with its co-opetition changing; Penalty costs and alliance cycle affect the stability of Competitive strategic alliance besides co-opetition.
\end{abstract}

Keywords: Co-opetition, competitive contractual strategic alliance, stability, system dynamics, Lotka-Voterra model

\section{Introduction}

Competitive contractual strategic alliance embodies two entirely different logic principles that contradict each other [1-2], which causes instability of competitive contractual strategic alliance. Usually, instability of such alliance means short and fragile cooperation, and the failure of alliance [3]. Accordingly, to make the most of competitive contractual strategic alliance in global competition, the issue of instability has to be solved.

However, there are few studies done to examine the stability of competitive contractual strategic alliance. The existing ones mainly focused on two aspects. One is the movement of two contradicting forces, competition and cooperation, and their influence on the stability of alliance, such as Das and Teng's [4] and Feiqiong Chen and Liangcong Fan [5]. Such studies haven't taken enough into account the systematics and dynamics of alliances stability. The other is based on the similarity of enterprises to living organisms [6], regarding alliances as eco-systems. Also, ecological theories and models were applied in their study to analyze the influence of co-opetition on strategic alliance's stability, such as Yongming Sheng, Weiguo Zhang and Xuemei Qing [7]. In Literature [8-14], classical logistic model and Lotka-Voterra model based on classical logistic model were applied to analyze the influence of co-opetition on strategic organizations' (including strategic alliances and networks) stability. These studies 
still didn't analyze alliance system's dynamic operation process. Besides, classical logistic model was applied to the circumstances of enterprise's growth surpassing its limit.

To make for the deficiencies of existing studies, this paper constructed system cycle diagram using system dynamics, and developed the dynamics equation, i.e., Lotka-Voterra model, for competitive strategic alliance based on contract by applying modified logistic model, so as to discuss the influence of co-opetition on such alliance.

\section{Stability Mechanisms of Competitive Contractual Strategic Alliance: the Construction of Modified Lotka-Voterra Model}

\subsection{The System of Competitive Contractual Strategic Alliance}

From the perspective of system theory, a system is the integration of interrelated and interacting elements, and all things in real world exist and operate by means of system. Competitive contractual strategic alliance is an open and complicated system.

With the establishment and operation of alliance, its target and performance come into play. The operation and control of alliance need to be continuously evaluated in term of performance, and compared with its target. Gaps between target and performance require corresponding alliance control and management. Alliance system's cycle diagram is shown in Figure 1.

\subsection{The Stability Mechanisms of Competitive Contractual Strategic Alliance}

Competitive contractual strategic alliance is institution arrangement. At the same time, it is also an ecological system, the stability of which features both system balance and ecological stability. The ultimate goal of any alliance, whatever motives it might have, is to acquire appropriate financial return. Profit that has been or will be obtained is going to affect alliance partners' current and next co-opetition decision, and it is also dictates strategic options, such as joining an alliance or not, the time to join and staying in the alliance or not. An alliance's performance is the deciding factor of its stability [15].

Market similarity and contractual control discriminate competitive contractual strategic alliance from other types of alliances. Market similarity dictates that alliance partners are no more than competitors to each other. Contractual control is not only incapable of eliminating competition from partners, but also generates derivations, such as learning competition and bargaining. The former is referred to as original competition, whereas the latter is called inter-alliance competition. Both types of competitions exist in an alliance, always and everywhere, affecting each other and cooperation between partners. The three of them are reciprocal to each other, mutually benefiting, integrating and forming into the co-opetition in competitive contractual strategic alliance. And the alliance's performance is affected by co-opetition, and dictates the stability of an alliance. Accordingly, the stability mechanism of competitive contractual strategic alliance is shown in Figure 2. 

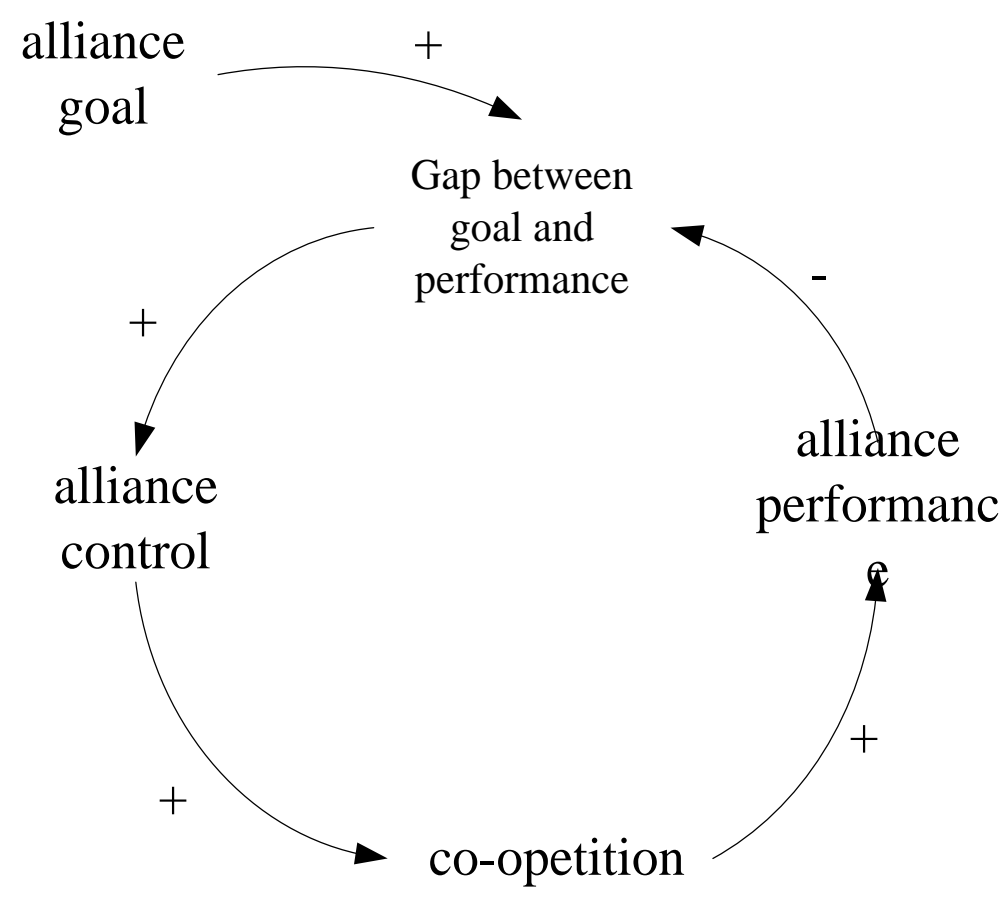

Figure 1. System Cycle Diagram of Competitive Contractual Strategic Alliance

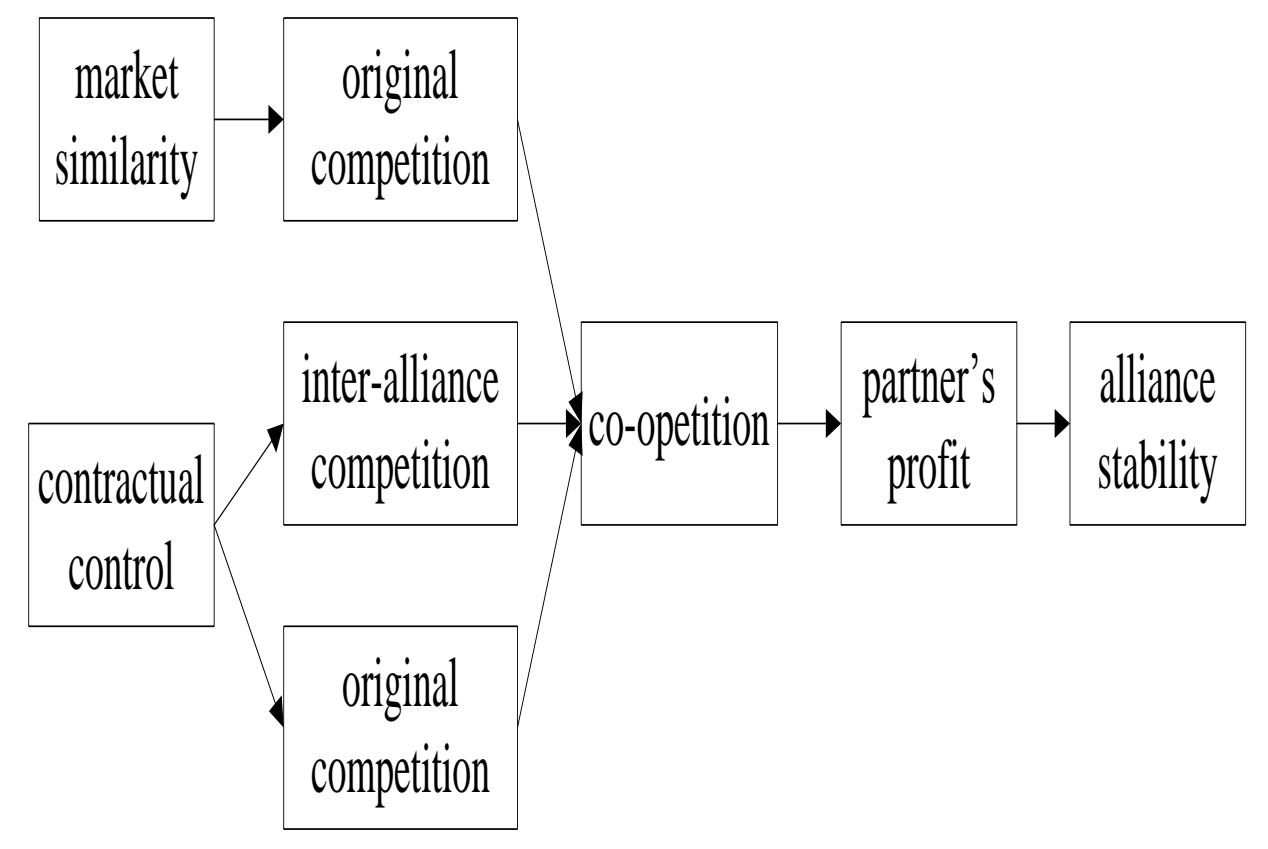

Figure 2. The Stability Mechanism of Competitive Contractual Strategic Alliance $^{1}$

\footnotetext{
${ }^{1}$ Alliance in the Figure is referring to specifically the Competitive contractual strategic alliance.
} 


\subsection{Constructing Lotka-Voterra Model for Competitive Contractual Strategic Alliance}

2.2.1. Co-opetition Definition: Corresponding intensity of co-opetition is defined as follows: Partner $i$ 's intensity of co-opetition $c_{i j}$ : co-opetition's degree of influence on alliance partner $i$, the variation of partner $i$ 's profit growth rate caused by partner $j$ 's profit change, i.e., : $\quad c_{i j}=\frac{\partial}{\partial R_{j}}\left(\frac{d R_{i}}{d t}\right)=\operatorname{com}_{0 i}+\operatorname{com}_{i}+\operatorname{coo}$

In the equation, $R_{i}$ is the profit of partner ${ }_{i}$, a continuously differentiable function of time $t$; $\frac{d R_{i}}{d t}$ is the profit growth rate of partner $i ; \operatorname{com}_{0 i}$ is the intensity of original competition, whereas com is the alliance partner $i$ 's intensity of inter-alliance competition; coo is the alliance partner $i$ 's intensity of cooperation; $\left(\operatorname{com}_{i}^{\prime}+\operatorname{coo}_{i}\right)$ is the inter-alliance co-opetition effect, namely the alliance effect, $i, j=1,2, i \neq j$. Notably, the symbol ' + ' means merging, not adding.

2.2.2. Lotka-Voterra Model for Competitive Contractual Strategic Alliance: In ecology perspective, enterprises are intelligent living organism with vital signs [16-17]. As for contractual alliance built by two competing enterprises, co-opetition between partners is similar to the interaction between biotic groups, which constitute de facto an eco-system.

According to ecological theories, under the condition of partner's individual existence, growth rate of partners' profit follows classical logistic model, whereas alliance's growth rate follows Lotka-Voterra model [18], thus:

$$
\frac{d R_{i}}{d t}=R_{i} b_{i}\left(1-\frac{R_{i}}{N_{i}}\right)
$$

In the equation, $t$ denotes time, since factors affecting profit level can be deemed as functions of time, such as technology, information, professionalism, division of labor, investment and transaction cost. As a result, time t not only includes its everyday meaning, but also all the variations that are influencing enterprises' profit level. $b_{i}$ denotes partner $i$ 's internal growth rate, namely the enterprise's growth rate decided by partner's own internal characteristics, and usually $b_{i}>0 \cdot N_{i}$ denotes the maximum profit partner $i$ can acquire without the variations of time, location and resource.

In equation (1), when $b_{i}<0$ and $R_{i}>N_{i}$ (alliance's profit surpasses its limit), calculation results in a unreasonable outcome, i.e. $\frac{d R_{i}}{d t}>0$. Therefore, classical logistic model has been modified by T. G. Hallam and C. E. Clark as follows:

$$
\frac{d R_{i}}{d t}=R_{i}\left(b_{i}+c_{i i} R_{i}\right) \quad(i=1,2)
$$

In equation (2), $c_{i i}$ denotes the restriction of necessary investments for partner $i$ 's profit growth factors, such as resources and environment, reflecting the enterprise's own retardant growth effect, and $c_{i i}<0$.

Before alliance, the two partners ${ }^{2}$ are only competitors. However, they are competing and cooperating at the same time. Besides affecting co-opetition between partners, contractual control dictates that the number of subject within an alliance is same as that of partners. Then,

2 To facilitate discussion, the number of alliance partners is limited to 2 . 
the partners' profit in a competitive contractual strategic alliance follows modified Lotka-Voterra model:

$$
\left\{\begin{array}{l}
\frac{d R_{1}}{d t}=R_{1}\left(b_{1}+c_{11} R_{1}+c_{12} R_{2}\right) \\
\frac{d R_{2}}{d t}=R_{2}\left(b_{2}+c_{21} R_{1}+c_{22} R_{2}\right)
\end{array}\right.
$$

Definition: $u_{i}=\frac{R_{i}(t)}{N_{i}}$ denotes partner $i$ 's actual market share at time $t$. Obviously, $R_{i}$ is positively correlated to $u_{i}$, and in case of partner $i$ 's individual existence, $0 \leq u_{i} \leq 1$; before alliance, $0 \leq u_{i}<1$; after, $u_{i} \geq 0$.

Let $\sigma_{12}=-c_{12} / c_{11}, \quad \sigma_{21}=-c_{21} / c_{22}, \quad \varepsilon_{1}=\frac{N_{2}}{N_{1}} \sigma_{12}, \quad \varepsilon_{2}=\frac{N_{1}}{N_{2}} \sigma_{21}$, then model (3) becomes:

$$
\left\{\begin{array}{l}
\frac{d u_{1}}{d t}=b_{1} u_{1}\left(1-u_{1}+\varepsilon_{1} u_{2}\right) \\
\frac{d u_{2}}{d t}=b_{2} u_{2}\left(1-u_{2}+\varepsilon_{2} u_{1}\right)
\end{array}\right.
$$

This is the modified Lotka-Voterra model based on modified logistic. Obviously, $\varepsilon_{i}$ is positively correlated to $c_{i j}$, and capable of reflecting partner $i$ 's degree of co-opetition. The value of $\varepsilon_{i}$ denotes the influence of alliance partner ${ }_{j}$ 's market share fluctuations has on alliance partner $i$ 's make share growth rate $(i \neq j)$.

\section{Model Analysis}

\subsection{Equilibrium}

There are four equilibriums in model (4): $P_{1}(0,0), P_{2}(0,1), P_{3}(1,0)$ and $P_{4}\left(\frac{1+\varepsilon_{1}}{1-\varepsilon_{1} \varepsilon_{2}}, \frac{1+\varepsilon_{2}}{1-\varepsilon_{1} \varepsilon_{2}}\right)$. Since equilibriums are the system's fix points, representing the ultimate state of systematic development. In terms of competitive alliance systems based on contracts, the ultimate state of profit must be a non-negative value. As a result, only when $P_{4}$ is a positive equilibrium point, the model makes sense.

According to the theory of stability, equilibrium point $P_{1}$ is unstable under any circumstances; equilibrium point $P_{2}$ gradually stabilizes when $\varepsilon_{1}<-1$; equilibrium point $P_{3}$ gradually stabilizes when $\varepsilon_{2}<-1$; equilibrium point $P_{4}$ stabilizes gradually when $\varepsilon_{1}>-1$ 、 $\varepsilon_{2}>-1$ and $\varepsilon_{1} \varepsilon_{2}<1$, as indicated in Table 1 . 
Table 1. Stability Conditions of All Equilibrium Points

\begin{tabular}{|c|c|c|}
\hline $\begin{array}{c}\text { Equilibrium } \\
\text { Point }\end{array}$ & Stability Condition & Stability \\
\hline$P_{1}$ & Unstable under any conditions & Unstable \\
\hline$P_{2}$ & $\varepsilon_{1}<-1$ & Gradually \\
& & stable \\
\hline$P_{3}$ & $\varepsilon_{2}<-1$ & Gradually \\
& $\varepsilon_{1}>-1$ & stable \\
& $\varepsilon_{2}>-1$ & Gradually \\
& $\varepsilon_{1} \varepsilon_{2}<1$ & stable \\
\hline
\end{tabular}

\subsection{Co-opetition and the Stability of Alliance System}

In terms of competitive contractual strategic alliance, there are three possible outcomes, including disintegration, merger and stabilization. For each equilibrium: $P_{2}$ and $P_{3}$ represent that one alliance partner merged another. For equilibrium $P_{2}$ and $P_{3}$, if alliance lasts long enough, one of the partners will be merged; and the alliance will disintegrate if otherwise. Positive equilibrium point $P_{4}$ represents that all alliance partners has acquired maximum financial return under existing conditions. It proves alliance partners' profit is higher than before with only competitions, and the partners are lack of motivation to leave: the alliance remains stable.

Original competition is decided by the business scope and will not disappear with establishment of alliance: $\operatorname{com}_{0 i}<0$ is true all the way through alliance. Inter-alliance competition and cooperation constitute all together inter-alliance co-opetition. For alliance to sustain, inter-alliance co-opetition effect, i.e. alliance effect must stay positive, thus $\mathrm{com}_{i}<0$, $c o o_{i}>0$, and $c o m_{i}+\operatorname{coo}_{i}>0$. Accordingly, in terms of competitive strategic alliance system based on contract, alliance partner's co-opetition $\varepsilon_{i}$ is possibly both positive and negative.

By examining the stability of all equilibrium points, it is found that the degrees of co-opetition are located in different range and the states of stability on each point are different from each other, thus the evolution outcomes of competitive contractual strategic alliance varies, which is shown in Figure 3.

\subsection{Stability Boundaries}

Positive equilibrium point $P_{4}$ approaches stability gradually, indicating that competitive contractual strategic alliance is stable. From the stability conditions of equilibrium point $P_{4}$, the alliance is table when the degree of alliance partner's co-opetition is located in the range 
of $\varepsilon_{1}>-1 、 \varepsilon_{2}>-1$ and $\varepsilon_{1} \varepsilon_{2}<1$, meaning in this range, although the degree of alliance partners' co-opetition is possibly changed for adaptation, but the alliance remains stable and the system has resistance and recoverability. Outside of this range, the alliance's stability is breached and the alliance cannot continue. Accordingly, the stability boundaries of competitive contractual strategic alliance is obtained and shown in Figure 4.

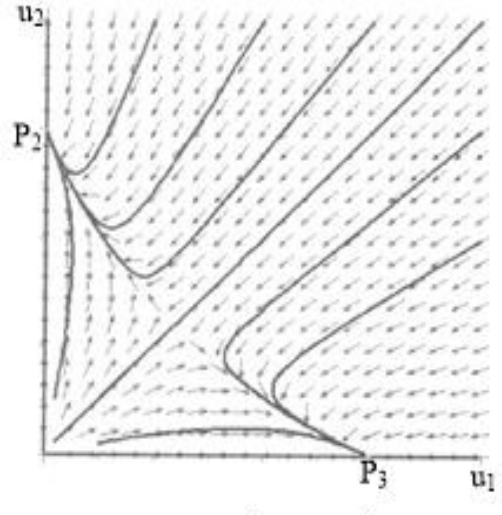

$\varepsilon_{1}<-1, \varepsilon_{2}<-1$

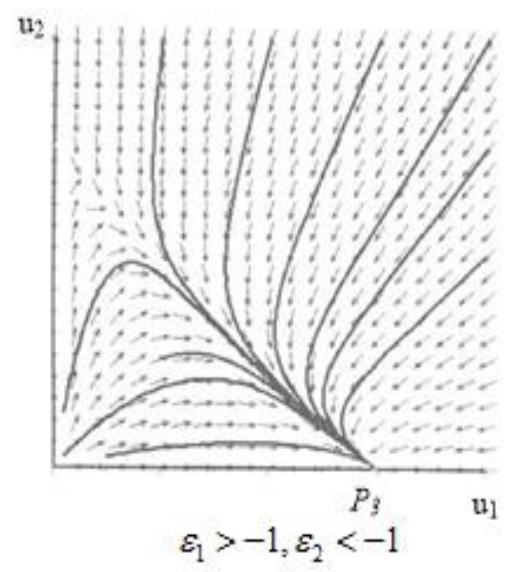

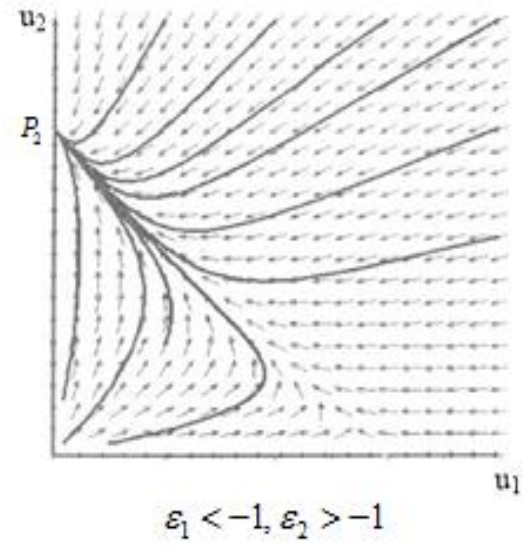

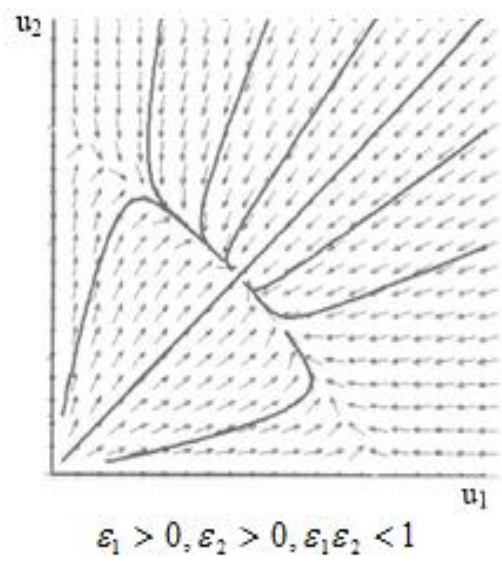

Figure 3. Alliance System Evolution with Different Co-opetition 


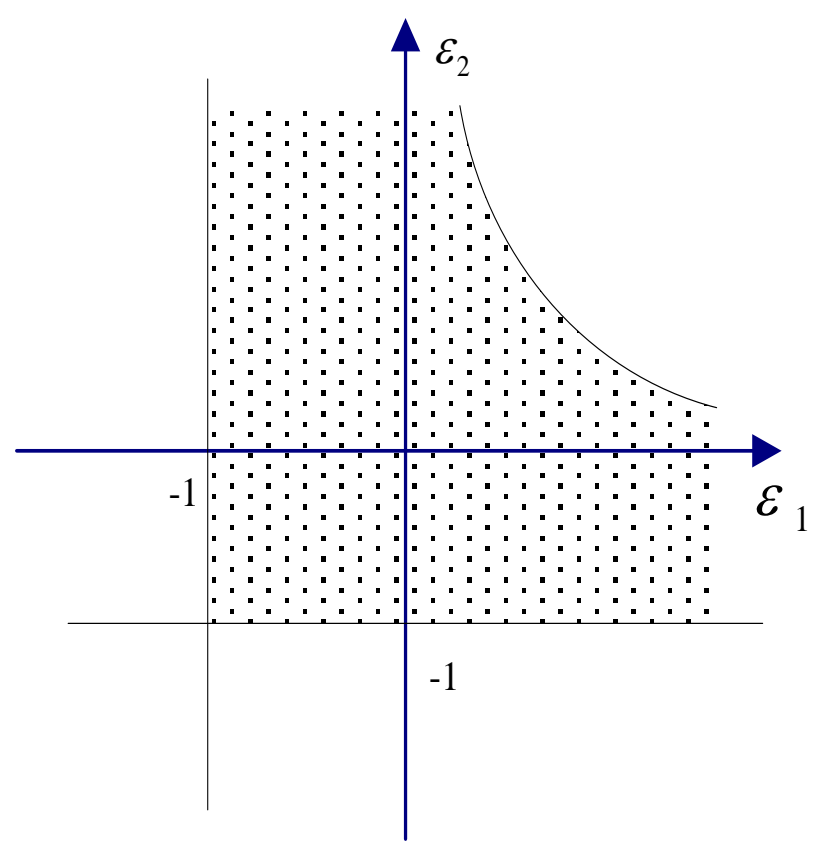

Figure 4. The Stability Boundaries of Competitive Contractual Strategic Alliance

\section{Further Discussion of the Model}

\subsection{Co-opetition, Penalty cost, Alliance Cycle and Stability}

Competitive contractual strategic alliance has three different outcomes, including disintegration, merging and co-existence (passive co-existence and stable co-existence), which correspond to equilibrium points $P_{2} 、 P_{3}$ and $P_{4}$. Alliance's control and the realization of its target is time consuming. As a result, the actual outcome of alliance evolution is affected by not only the degree of alliance partner's co-opetition, but also alliance cycle and penalty cost. If the alliance's penalty cost is too high, the exit standards will be raised accordingly. From the stability conditions of all equilibrium points, as long as the degree of co-opetition is too low for one of the alliance partners, competition effect is far more intense than co-opetition effect, i.e. the degree of co-opetition $\left(\varepsilon_{1}, \varepsilon_{2}\right) \in<\left\{\left(\varepsilon_{1}, \varepsilon_{2}\right) \mid \varepsilon_{1}<-1\right\} \cup\left\{\left(\varepsilon_{1}, \varepsilon_{2}\right) \mid \varepsilon_{2}<-1\right\}$. If penalty cost is too high and alliance cycle is long enough, the passive co-existence of alliance partner (s) will evolve into merging. However, if penalty cost is too low, no matter how long the cycle is, the alliance will end up with disintegration.

\subsection{Co-opetition Evolution and the Stability of Competitive Contractual Strategic} Alliance

The stability of competitive contractual strategic alliance is a systematic characteristic manifested under the influence of a series of factors that can be put into competition and cooperation [19] carrying on simultaneously, i.e. co-opetition. After the establishment of alliance, co-opetition between alliance partners is not always be the same, but changing 
constantly. The continuous motion of co-opetition is the impetus of alliance system's evolution, which place the system in different state of stability.

Assume that the equilibrium point of model (4) is $\left(u_{1}^{*}, u_{2}^{*}\right)$, since when $\varepsilon_{i}>0$, the alliance's stability boundary is not a straight line but hyperbola. To facilitate discussion, it is assumed that $\varepsilon_{2}=\frac{1}{2}$ (discussion remains the same when $\varepsilon_{2}$ varies). Then, the change of alliance partner 1 's equilibrium point is shown in equation (5) and Figure 5:

$$
u_{1}^{*}= \begin{cases}0 & \varepsilon_{1} \leq-1 \\ \frac{1+\varepsilon_{1}}{1-\varepsilon_{1} \varepsilon_{2}} & -1<\varepsilon_{1}<2 \\ 0 & \varepsilon_{1} \geq 2\end{cases}
$$

Out of the same consideration, $\varepsilon_{1}=2$ is an assumed value for the discussion of alliance partner 2's equilibrium state changing with co-opetition evolution. Then, the actual market share equilibrium solution of alliance partner 2 is shown in equation (6) and Figure 6:

$$
u_{2}^{*}= \begin{cases}0 & \varepsilon_{2} \leq-1 \\ \frac{1+\varepsilon_{2}}{1-\varepsilon_{1} \varepsilon_{2}} & -1<\varepsilon_{2}<\frac{1}{2} \\ 0 & \varepsilon_{2} \geq \frac{1}{2}\end{cases}
$$

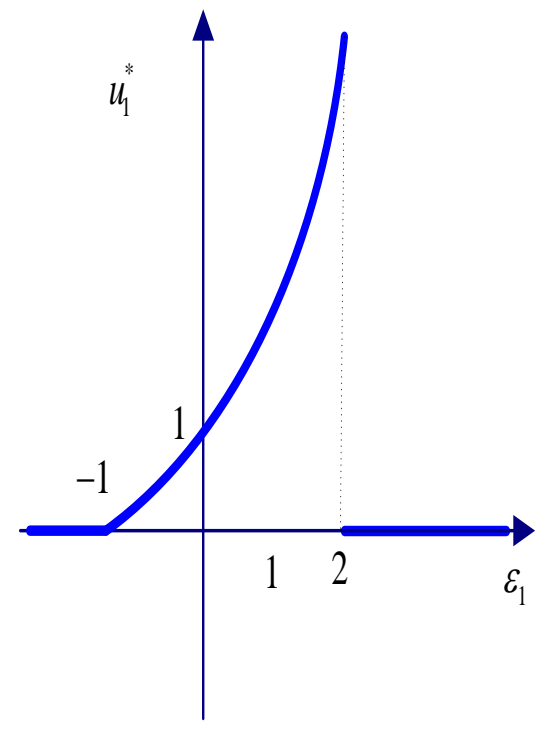

Fig.5 The Diagram of Alliance

Partnerl's Equilibrium Evolution with Co-opetition

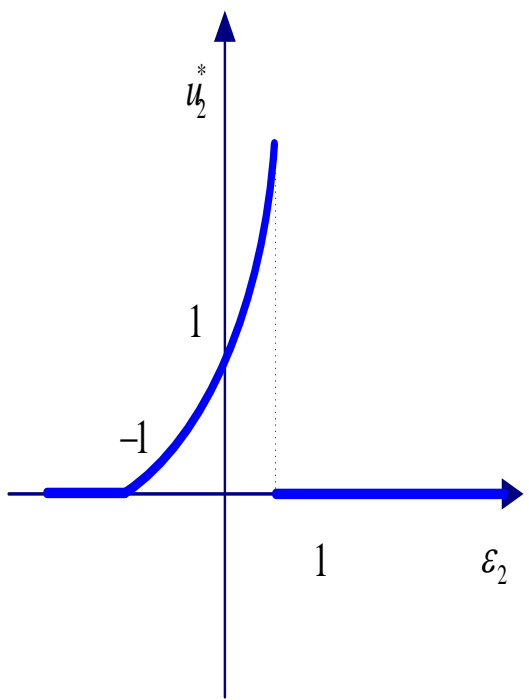

Fig.6 The Diagram of Alliance

Partner2's Equilibrium Evolution with Co-opetition

From equation (5), (6) and Figure (5), (6), it's obvious that the partners' equilibrium profits varies with its co-opetition changing. 


\section{Conclusion}

Original competition, inter-alliance competition and cooperation constitute all together co-opetition relations in competitive contractual strategic alliance. Co-opetition influences alliance partners by means of affecting their profit, so as to decide the stability of competitive contractual strategic alliance. Under the condition of partner's individual existence, its growth rate follows modified classical logistic model, whereas alliance's growth rate follows Lotka - Voterra model.

Through analyzing the modified Lotka - Voterra model, it is found:

(1)The differences of co-opetition degree result in different outcomes of alliance system's evolution. A stable state is achievable when $\varepsilon_{1}>0, \varepsilon_{2}>0, \varepsilon_{1} \varepsilon_{2}<1$; Either over competition(ie. $\varepsilon_{i}<-1$ ) or over cooperation (ie. $\varepsilon_{i}>0, \varepsilon_{1} \varepsilon_{2}>1$ ) is adverse for the stability of alliance system. Then the stable boundary exists.

(2) Co-opetition between alliance partners is not always the same, but changing constantly. The continuous motion of co-opetition places the alliance in different state of stability, such as disintegration, merging and stability.

(3) Penalty costs and alliance cycle affect the stability of Competitive strategic alliance besides co-opetition, which should be paid more attention.

\section{Acknowledgements}

This work was supported by Grants from MOE (Ministry of Education in China) Project of doctoral section (no. 20100191110039).

\section{References}

[1] C. C. Hill, H. Li and B. Davies, "The paradox of cooperation and competition in strategic alliances: Towards a multi-paradigm approach", Management Research News, vol. 26, no. 1, (2003), pp. 1-20.

[2] M. Zineldin, "Co-opetition the organization of the future", Marketing Intelligence \& Planning, vol. 22, no. 6-7, pp. 780-789.

[3] K. Zhang, "Study on Strategic Alliance Instability Base on Game Theory", Shanxi University, (2010).

[4] T. K. Das and B. S. Teng, "Instabilities of strategic alliances: an internal tensions perspective", Organization Science, vol. 11, no. 1, (2000), pp. 77-101

[5] F. Q. Chen and L. C. Fan, "Stability Analysis of Strategic Alliances Based on Cooperation and Competition", Management World, no. 7, (2007), pp. 102-110.

[6] P. N. Ruan, J. W. Zhang and Y. Li, "Study of Priciple and Mannagement of Relation among Nodes in Strategic Networks", Science of Science and Management of S.\& T, vol. 29, no. 4, (2008), pp. 157-160.

[7] Y. M. Sheng, W. G. Zhang and X. M. Qing, "Study on the Stability of Co-opetitive Strategic Alliance", Statistics and Decision, no. 10, (2009), pp. 42-45.

[8] M. X. Wang, "Research on the Evolution Mechanism about Competitive Strategic Alliance System of Enterprise", Yanshan University, (2010).

[9] C. Y. Gao and P. Du, "The Cooperation and Competition Model of Inter-members in High-tech Virtual Industrial Cluster Based on Lotka-Volterra", Science \& Technology Progress and Policy, no. 12, (2009), pp. $72-75$.

[10] B. Han and Qi Meng, "Analysis on System Structure Evolution for the Forming of Strategic Alliance Synergy Mechanism", Science \& Technology Progress and Policy, no. 11, (2007), pp. 37-40.

[11] Y. Y. Wu and P. C. Mang, "Study on the Stability of Strategic Networks Based on Enterprise Ecology", Science \& Technology Progress and Policy, no. 6, (2010), pp. 93-97.

[12] X. Z. Zhuo, X. Wang and Z. F. Wang, "A Study on the Coopetition Relationship among Allied Partners of Supply Chain Enterprises Based on the Volterra Model", Journal of Industrial Engineering and Engineering Management, vol. 24, no. 1, (2010), pp. 134-137. 
[13] H. X. Ye, P. Z. Zhang and J. Sun, "Dynamic Cooperation-competition in Interest-group", Journal of Industrial Engineering and Engineering Management, vol. 16, no. 1, (2002), pp. 62-66.

[14] Y. Yan and M. Q. Li, "Dynamic Analysis of Network Organizations' Evolution Based on Co-opetition Relation", Systems Engineering, vol. 27, no. 10, (2009), pp. 98-103.

[15] X. Ren and Z. P. Zhang, "Mechanism of Strategic Alliance Evolution Based on Alliance Performance", International Conference on Engineering and Business Management, (2011), pp. 403-406.

[16] Z. Z. Yang, "Introduction to Enterprise Ecology", Science Press, Beijing, (2003).

[17] Y. Lou and H. Zhao, "The Model of Enterprises Ecosystem and the Analysis of Abiotic Environment Factors", The Journal of Quantitative \& Technical Economics, no. 3, (2002), pp. 61-64.

[18] L. Z. Liu, B. Wu and W. X. Sun, "On the Stability of Strategic Alliance of Technological Innovation: Development Model Study", Science \& Technology Progress and Policy, no. 3, (2012), pp. 62-64.

[19] J. R. Cai, "Partner Characteristics, Credible Commitment and the Stability of Strategic Alliances", Science of Science and Management of S. \& T, no. 7, (2012), pp. 133-142.

\section{Authors}

Xuemei Qing, she is a doctoral candidate in the school of Economics and Business Administration, Chongqing University, China. Her research interests include strategic management and Econometrics.

Weiguo Zhang, he is a Professor in the School of Economics and Management, Chongqing University, China. His research interests are in the fields of strategic management, knowledge management and financial management. 
International Journal of $u$ - and e- Service, Science and Technology Vol.8, No.1 (2015) 